\title{
45 - Ocorrência de helmintos e protozoários em cães capturados da cidade de São João da Boa Vista-SP
}

1- Residente do Hospital Veterinário das Faculdades Integradas Fundação de Ensino "Otávio Bastos" área clínica médica, São João da Boa Vista-SP

2- Professor Doutor de Parasitologia das Faculdades Integradas Fundação de Ensino "Otávio Bastos" área clínica médica, São João da Boa Vista-SP

O crescente número de animais de companhia principalmente nos grandes centros, tem estreitado o contato entre os mesmos e o homem, aumentando a exposição humana a agentes causais de zoonoses, contudo a ocorrência de cães com parasitoses gastrointestinais tem despertado o interesse de pesquisadores em definir a freqüência do achado e estabelecer as espécies mais prevalentes em suas regiões. As parasitoses apresentam interrelação com o bem estar animal e a saúde pública, visto os danos causados nos animais e ao homem, a saber diarréia, vômitos, obstrução mecânica, anemia bem como as zoonoses, pois o convivio destes animais com o homem e principalmente com crianças tem gerado casos freqüentes causados por parasitos desta população como, por exemplo, Toxocara canis responsável pela larva migrans visceral e larva migrans ocular, Ancylostoma caninum e Ancylostoma braziliense responsáveis pela larva migrans cutânea e Giardia sp. responsável pela giardiase. O trabalho teve como objetivo investigar a freqüência de ocorrência de helmintos e protozoários em cães capturados da cidade de São João da Boa Vista, utilizando-se amostras fecais de cães oriundos de seu Centro de Controle de Zoonoses (CCZ) Enf. "Carmem L. Paione", onde as fezes eram colhidas diretamente do reto, acondicionadas em frascos tipo coletores universais e os intestinos eram retirados para análise, não se levando em conta idade, sexo, raça ou condição corporal, o procedimento laboratorial foi desenvolvido no Laboratório de Parasitologia da Faculdade de Medicina Veterinária da Fundação de Ensino "Octávio Bastos". As amostras fecais eram submetidas a flutuação com sulfato de zinco a $33 \%$, para pesquisa de ovos, cistos e/ou oocistos dos parasitas. Os intestinos eram abertos em toda sua extensão na procura de helmintos para comparar com os resultados obtidos na flutuação. Foram examinados neste estudo 108 animais, sendo $51(47,2 \%)$ dos animais eram fêmeas e 57 $(52,8 \%)$ machos. Do total examinado à flutuação $66(61,1 \%)$ apresentaram-se positivas para uma ou mais espécies de parasitas, deste total $18(27,3 \%)$ apresentaram parasitismo múltiplo. Pelo exame dos intestinos, $108(100 \%)$ apresentaram-se positivos, sendo que 23 $(21,3 \%)$, apresentaram parasitoses múltiplas. Com os resultados obtidos neste trabalho, fica evidente a ocorrência de diagnósticos falso-negativos em relação as helmitoses quando compara-se os resultados obtidos na flutuação $(0,9 \%$ Dipylidium caninum; $33,3 \%$ Toxocara canis; 7,0\% Ancylostoma sp.) e inspeção dos intestinos (55,5\% Dipylidium caninum; 49,1\% Toxocara canis; $16,6 \%$ Ancylostoma sp.) dos mesmos animais. Tais resultados são de importância relevante, porque servem como alerta para que os pesquisadores possam investir mais no desenvolvimento de métodos mais precisos para o diagnóstico de helmintos intestinais, visto o alto número de resultados falso-negativos. Os dados obtidos comprovam o eminente risco de o homem adquirir doenças a partir do convívio com animais domésticos, pois os dois helmintos gastrointestinais mais freqüentes (Toxacara canis e Ancylostoma sp.) são responsáveis por zoonoses de grande importância em saúde pública (larva migrans cutânea, visceral e ocular), e o protozoário com grande prevalência, também considerado uma zoonose, causando a giardiase principalmente em crianças. 